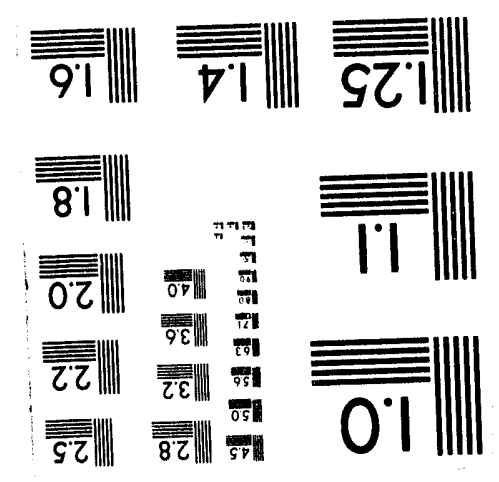



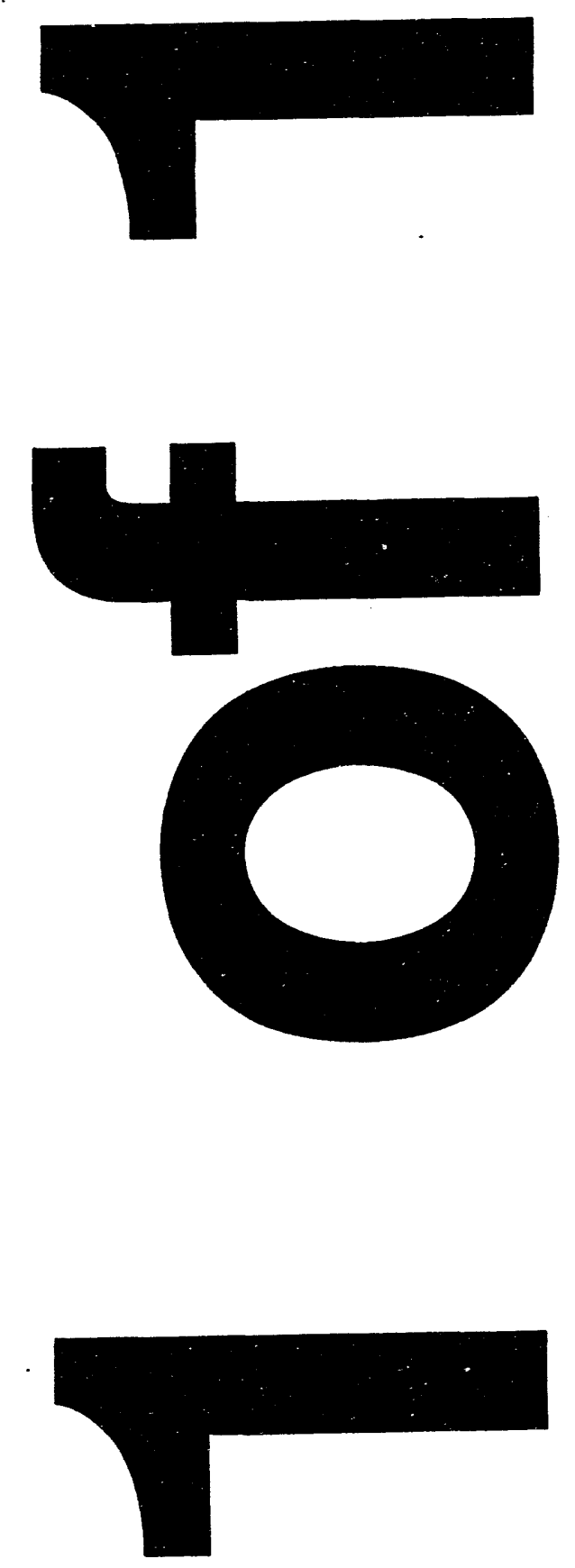
TITLE: TRITIUM EVOLUTION FROM VARIOUS MORPHOLOGIES OF PALLADIUM

AUthor(S): $\quad$ D. G. Tuggle, T. N. Claytor, and S. F. Taylor

SUBMitTED TO: Fourth International Conference on Cold Fusion Maui, Hawaii

December 6 to December 9, 1993

(Paper)

To be published in Fusion Techrology

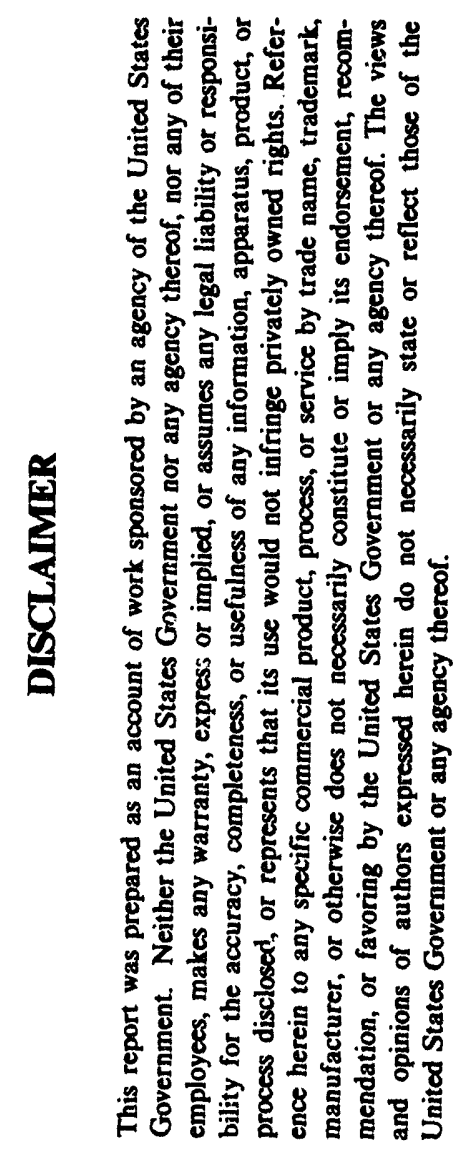

By acceptance of this arficle. the publisher recognizes that the U.S. Government retains a nonexclusive. royalty-Iree license to publish or reproduce the published form of this contribution. or to allow others to do so, for U.S. Government purposes.

The Los Alamos National Laboratory requests that the publisher identify this article as work performed under the auspices of the U.S. Department of Energy.
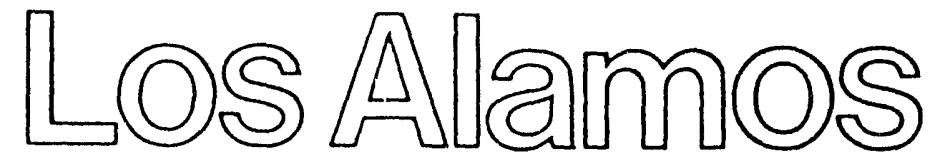

Los Alamos National Laboratory Los Alamos,New Mexico 87545 


\title{
TRITIUM EVOLUTION FROM VARIOUS MORPHOLOGIES OF PALLADIUM
}

\author{
D. G. Tuggle, T. N. Claytor and S. F. Taylor* \\ Los Alamos National Laboratory \\ Los Alamos, NM 87545 \\ *Affiliated with Brigham Young University
}

\begin{abstract}
We have been able to extend our tritium production techniques to various novel morphologies of palladium. These include small solid wires of various diameters and a type of pressed powder wire and a plasma cell. In the most successful experiments, the amount of palladium required, for an equivalent tritium output, has been reduced by a factor of 100 over our older powder methods. In addition, we have observed rates of tritium production $(>5 \mathrm{nCi} / \mathrm{h})$ that far exceed most of our previous results. Unfortunately, the methods that we currently use to obtain the tritium are poorly understood and consequently there are numerous variables that need to be investigated before the new methods are as reliable and repeatable as our previous techniques. For instance, it seems that surface and/or bulk impurities play a major role in the successful generation of any tritium. In those samples with total impurity concentrations of $>400 \mathrm{ppm}$ essentially no tritium has been generated by our gas loading and electrical simulation methods.
\end{abstract}

\section{INTRODUCTION}

The anomalous appearance of small amounts of tritium has been repeatedly observed in electrolytic and solid state gas loading experiments ${ }^{1-4}$. Some of these results were obtained with gas loaded discharge tubes operated at $25 \mathrm{kV}$, some with voltages as low as $50 \mathrm{~V}$ in electrolytic cells, and some with only cyclic hydriding and dehydriding of metal. The only readily common features in all the experiments are the presence of palladium (or other hydrided metal), deuterium and a disequilibrium condition for the deuterium. We will report on our tritium generation results from various morphologies of palladium subjected to periodic unipolar current pulses. These morphologies include wire, powder wire, and two types of plasma cells. The primary advantages of these experiments are that they are moderately reproducible, they produce readily detectable tritium levels in a few hours or days, and offer the possibility that they could be much more efficient.

In our previous work ${ }^{1}$, all tritium data was obtained from $20 \mathrm{~g}$ batches of oxidized palladium powder. In these experiments the amount of palladium involved is up to 40 times less and the water vapor problem is eliminated. All of the tritium data was obtained with on-line tritium gas monitors. One experiment was done in the batch mode because it was placed in a neutron counter in an underground laboratory.

Some have criticized the detection of tritium because the signals seem to be insignificant, tritium is ubiquitous, neutrons are not detected commensurate with the tritium generation rate, and the palladium metal is subject to possible tritium contamination. We will briefly discuss the possible avenues for contamination and show that each is negligible, or not a factor, in the experiments described. The magnitude of the signals discussed in this paper are multi-sigma and 
are often over a hundred times the tritium background in the supply gas. Furthermore, tritium may be the most sensitive and rapid indicator of anomalous nuclear behavior in deuterided metals. As such, it is well suited for rapid parametric investigations. The lack of a detectable neutron signal ${ }^{5}$ is distressing, but only if one assumes that the mechanism for tritium production produces energetic tritions (energies $>25 \mathrm{keV}$ ).

\section{MATERIALS}

The detailed analysis of our materials $\left(\mathrm{Pd}, \mathrm{Si}, \mathrm{H}_{2}, \mathrm{D}_{2}\right)$ has been described previouslyl. For this work we used, exclusively Cryogenic Rare Gases deuterium $99.995 \%$ that has $90 \mathrm{pCi} / 1$ of tritium. The major impurity in the deuterium is $\mathrm{H}_{2}(0.005 \%)(\mathrm{He}<1 \mathrm{ppm})$. A total of $168.8 \mathrm{~g}$ of palladium powder was used in our recent experiments described in this paper. This powder has been checked for tritium contamination by three independent methods. Of that amount, $39.4 \mathrm{~g}$ was used in various hydrogen control experiments. A total of $20.11 \mathrm{~g}$ of palladium foil and wire $(>99.99 \%)$ from Johnson and Matthey and Goodfellow was used in the wire and plasma cells; $1.63 \mathrm{~g}$ of this amount was checked for tritium contamination by heating.

All of the palladium has been subjected to rigorous metallographic and impurity analysis. Major impurities in the Engelhard palladium are oxygen $(980 \mathrm{ppm})$ Chlorine (80 ppm), Nitrogen (65 ppm) and Carbon (47 ppm). All other major impurities are (each) under $35 \mathrm{ppm}$ by weight. The impurity levels for the wires (Johnson Matthey Puratronic) varied from the specification sheet and were in the $150 \mathrm{ppm}$ range (all metals) rather than the quoted values of 5-10 ppm. The Goodfellow wire was analyzed at $66 \mathrm{ppm}$ rather than the $<10 \mathrm{ppm}$ listed in the analysis sheet supplied by the vendor. Repeated analysis of the same batch of wire gave up to a $50 \%$ variation in total impurity concentration. This is either intrabatch variation or, more likely, random analysis error.

The 220 micron thick foils were always annealed at $850^{\circ} \mathrm{C}$ for 2 hours at $10^{-6}$ torr before use. These foils have been hydrided, run in cells, dehydrided and annealed seven times and show neither a monotonic decrease nor increase in tritium production. The palladium powder was virgin powder and had been oxidized in air at $350^{\circ} \mathrm{C}$ for 2 hours. Wire from five batches (lots W13918, W06528, Z0114, NM 35680, GF5140) was obtained from Johnson Matthey and Goodfellow Metals. Only one of these batches (W 13918) showed large (16 to $298 \mathrm{nCi} / \mathrm{g}$ ) amounts of tritium.

Tritium contamination in the palladium powder was tested by three independent methods: dissolution and scintillation counting, hydriding and dehydriding and measurement ${ }^{6}$ of ${ }^{3} \mathrm{He}$. By these means we can assign an upper limit on tritium contamination of $0.005 \mathrm{nCi} / \mathrm{g}$ (i.e., no tritium detected within experimental error). The Goodfellow wire was tested for contamination (with null results) by analyzing a sequential $0.1 \mathrm{~g}$ of wire taken between wire samples shown to produce tritium in the experiments. Also, in an extensive independent ${ }^{7}$ investigation of palladium wire, several hundred samples were tested with no contamination present. The purity of the wire used in these experiments also weighs heavily against intrinsic spot contamination.

A total of 29 wire experiments were performed, six of these were powder wire. Separately, a total of four plasma experiments will be discussed. In addition, ten powder layered experiment (eight $\mathrm{D}_{2}$ and two $\mathrm{H}_{2}$ ) were also performed with nominal results, consistent with our previously reported results. However, because the results were obtained in a recently built tritium analysis system with a lower intrinsic background and no prior history of tritium contamination we consider these to be a positive confirmation of our previous results. 


\section{APPARATUS}

Shown in Figure 1 is the stainless steel gas analysis loop containing a three liter ion gauge and a $310.9 \mathrm{cc}$ calibration volume. The three pressure gauges $(0.2 \%)$, ion gauge and sample and room temperatures $\left(0.1^{\circ} \mathrm{C}\right)$ are recorded on a computer log at $60 \mathrm{~s}$ intervals. In operation, a solid state or plasma cell would be attached to the loop and hydrided in situ with deuterium or hydrogen or a mixture of gas. The pressure drop during hydriding or the resistivity of the wire was used as indicators of the stochiometry of the $\mathrm{PdD}_{\mathrm{X}}$. The environmental chamber also enables us to heat $(500 \mathrm{~K})$ and cool $(200 \mathrm{~K})$ the sample allowing various levels of stochiometry.

The Femtotech ion gauge rejects pulse type radioactive events that effectively discriminate against radon and cosmic ray ionization. Prior to this study, the Femtotech background (system 1) was usually between 1.8 and $2.2 \mathrm{nCi} / 1$ (due to particulate and tritium exposure of previous cold fusion cells) and had a relatively low drift rate, initially $(0.006 \mathrm{nCi} / \mathrm{h}-\mathrm{hr})$. After exposure to the cells described in this paper, the drift rate was considerably higher (often up to $0 . \operatorname{lnCi} / 1-\mathrm{hr}$ ) and was difficult to return to the baseline rate. Partway through the study a second system was built with a new Femtotech. The background with this new system (system 2) is near zero \pm 0.2 (at 600 torr) and it has a negligible drift rate $(<0.001 \mathrm{nC} / \mathrm{h}-\mathrm{hr})$.

The new loop is improved over our original loop because the Femtotech is heated at a constant temperature, there is an integral cold trap, and there is valving to allow the pressurization of the cell independent of the loop. Two 2 micron filters are installed at the inlet of the ion gauge and at the outlet of the cell to eliminate spurious responses due to particulates. A pressure gauge at the Femtotech also directly measures the ionization gauge pressure even with flow in the loop.

A hydrogen oxidation system was built to act as a backup test for tritium using a scintillation counter (Packard 9600). Calibration $\mathrm{D}_{2}$ gas with $25 \mathrm{nCi} / 1$ of tritium was used to test the two Femtotechs and the oxidation system. The two ionization systems agree to within $5 \%$ of each other while the scintillation results were about $30 \%$ lower than the Femtotechs. Not enough runs have been completed with the oxidation system to optimize the tritium collection as a function of gas flow at this time.

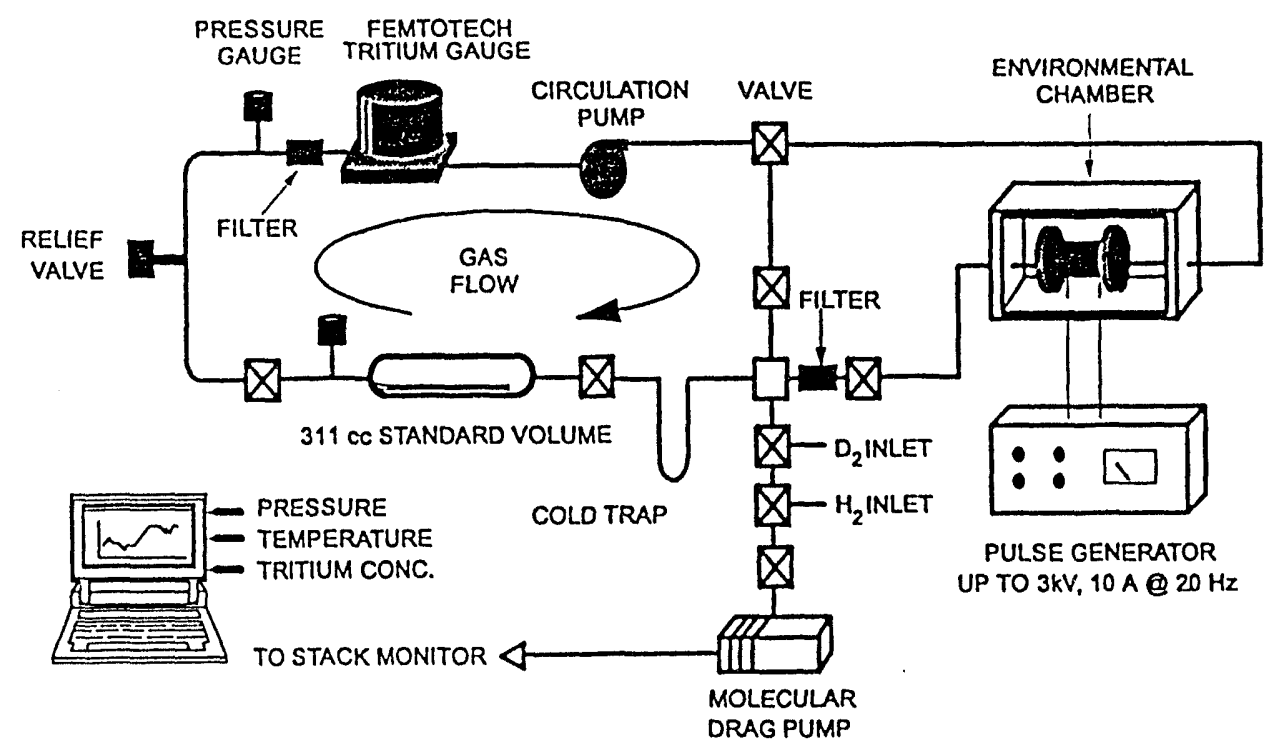

Figure 1. The new tritium analysis system (system 2) used in the second half of this study. 


\section{PROCEDURE}

The procedure for hydriding a wire or Pd-Si cell was to first fill the 3.1 liter loop with deuterium gas at 600 to 1200 torr and measure the background tritium concentration, if possible. The gas would then be circulated around the loop for 12-24 hours to determine the background drift rate. With the loop drift rate measured, fresh deuterium was introduced into the loop and the cell hydrided slowly with the deuterium flowing in the loop. With the system 2 , the drift rate is so low that these steps can be eliminated.

After a cell had been hydrided, the gas was circulated with the cell in place from 15 minutes to several days to ensure that no tritium was evolving from the palladium and to allow the palladium to fully hydride. With wire cells it was a simple matter to measure the resistance of the wire to determine the hydride state. With the plasma cells, a wait of 24 hours was used to ensure the foils and wires were hydrided. As received (100 micron) wires would typically hydride in $12-$ 18 hours, wires that had been cleaned with alcohol and by scraping with a $\mathrm{Al}_{2} \mathrm{O}_{3}$ plastic polishing cloth ( 3 micron) took about 6 to 8 hours to hydride. Wires that had been cleaned and then annealed ( $350^{\circ} \mathrm{C}$ for $2 \mathrm{~h}$ in air), hydrided within 15 to 30 minutes.

To dehydride the wires, a large dc current $(0.6$ to $0.8 \mathrm{~A})$ was run through the wire, or the whole cell was heated to over $150^{\circ} \mathrm{C}$. Powder samples were dehydrided by heating to $473 \mathrm{~K}$ with the environmental chamber. A final dehydride could be accomplished by closing off the cell, evacuating the loop, and then opening the hot cell to vacuum. The last $6-10 \%$ of the deuterium could be recovered by this method. The plasma cells were dehydrided by simply evacuating the loop and drawing off as much deuterium from the plasma cell as possible at room temperature.

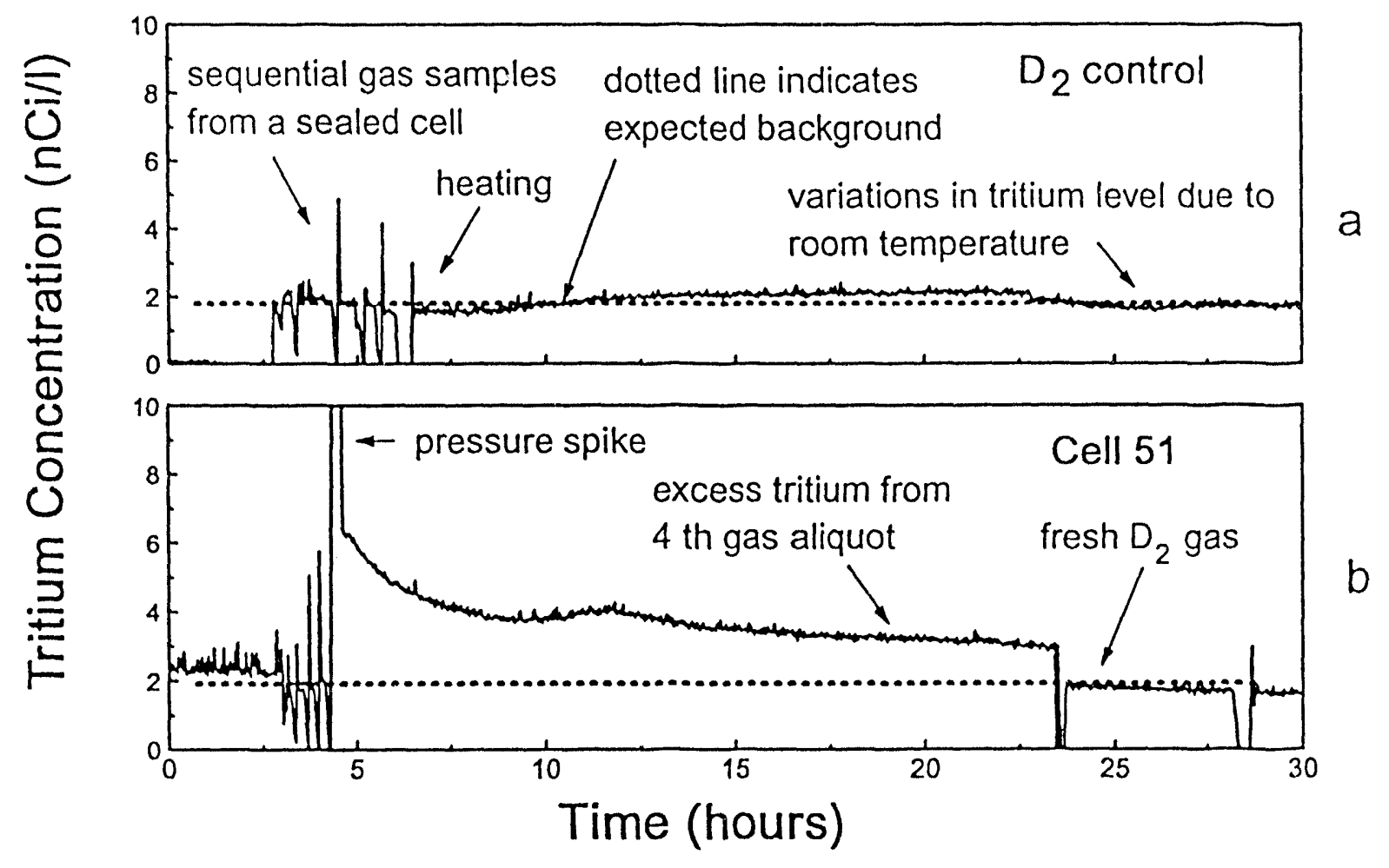

Figure 2. Comparison of background and foreground results with a $\mathrm{Pd}-\mathrm{Si}$ layer powder type cell. 


\section{RESULTS}

A summary of the various experiments is as follows. There were a total of 29 wire and powder wire experiments, 4 plasma cell experiments as well as ten $\mathrm{Pd}$-Si powder cell experiments. These are grouped by type but it should be understood that, generally, the wire and powdersilicon types were run near the beginning of this series of experiments and some of the earlier experiments were done with system 1 .

\section{Pd-Si Cells}

Two of the Pd-Si cells were run underground at BYU; the first cell shorted and gave only $1 \pm 0.3 \mathrm{nCi}$, the tritium results for the second cell are shown in Figure 2 with a background. The largest tritium output (for this cell type), in the series of cells run with the clean system was with cell 56 that gave $13.5 \mathrm{nCi}$ as compared to background runs of either hydrogen or deuterium that gave $6.5 \pm 0.2 \mathrm{nCi}$. The tritium evolution rates were commensurate with the rates obtained in system $1(0.05$ to $0.3 \mathrm{nCi} / \mathrm{hr})$ for active cells.

Shown in Figure 2 is a dehydride of a cell that was run for about 105 hours in the BYU tunnel in a sealed sample chamber with $4 \mathrm{~atm}$. deuterium pressure. As indicated in the figure, 600 torr aliquots of gas were removed from the sample cell after an initial 600 torr fill from the original $\mathrm{D}_{2}$ cylinder was used to check the response of the system. Also shown in Figure $2 \mathrm{a}$ is a sample of palladium powder of the same batch as sample 51 that was put in the sample chamber and deuterided and dehyrided with the same pressure as sample 51. The control sample was not pulsed. It is seen that after the control sample is heated to dehyride the palladium, a decrease in the apparent tritium level is observed. This is due to the quenching effect of water on the ionization current. Sample 51 shows a completely different behavior, when heated. The apparent tritium level increases and then decreases, presumably due to mixing. We attribute this to the presence of tritiated water vapor from the cell. The fact that the tritium level is still dropping at the end of the test when the deuterium is pumped out created an uncertainty in the measured level. The other revealing feature of cell 51 is that the tritium level, in the first three aliquots increases with each sample, slightly, whereas, the samples from the inactive cell decrease with each sample due to an increased concentration of water vapor in the latter samples.

The total amount of tritium evolved from cell 51 is only $5.1 \pm 1.5 \mathrm{nCi}$. To put this number in perspective with the rest of our measurements, it should be noted that about $28 \%$ of the cells produced tritium $>15 \mathrm{nCi}$, while about $34 \%$ of the samples give reading of between 0 and $5 \mathrm{nCi}$. The result from cell 51 is entirely consistent with data taken over two years ago with a completely different ionization gauge and deuterium with a tritium concentration of up $100 \mathrm{nCi} / \mathrm{l}$. In the recent experiment and in the historical cases, most of the tritium was evolved when the palladium was dehydided. For these most recent experiments the sensitivity and accuracy of the measurements far exceeds the prior data because the intrinsic tritium level $(90 \mathrm{pCi} / \mathrm{l})$ is inconsequential and consequently the separation factor is negligible.

\section{Solid Wire Cells}

Of the 29 wires that were run, 7 of these were of the powder type (Figure 3c ), the rest were bare palladium wire wrapped on a grooved macor ceramic spool. Of the wires, only one batch (W13918) from Johnson and Matthey showed consistent tritium production over $0.1 \mathrm{nCi} / \mathrm{hr}$. All of this wire came from one spool, and another, supposedly identical batch, from another spool 
did not show any significant production in systen 2 . The rest of the solid wires, whether they were run in system 1 , system 2 or in a sealed pressure vessel were rather unproductive, for instance, wire ten gave $4.2 \mathrm{nCi}$ total in system 2 after 380 hours of pulsing at high currents (11 amps peak). All other wires we ran gave an average of $1.0 \mathrm{nCi}$ after 133 hours of operation. Most of the wires were 100 microns in diameter, but wires were fabricated with diameters of 112 , 152, 203 and 254 microns in lengths of 100 to $500 \mathrm{~cm}$. For a given material and length of wire, the smaller wires produced more tritium than the larger diameters even though they contained much less material. Most of the wire was run in the as received condition, but one wire was run after being annealed in air at $600{ }^{\circ} \mathrm{C}$. This procedure did not noticeably affect the tritium generation rate. Another wire was contaminated with chlorine on the surface and did not hydride or produce any tritium.

Most of the batches (excluding batch W13918) of wire showed considerable contaminants including microscopic (100x) carbon deposits on the wire. To illustrate just how deleterious this might be, we electrically heated one batch (W06528) to about $500{ }^{\circ} \mathrm{C}$ in air and witnessed a visible smoke from the wire. A yellow-brown residue was left on the otherwise white ceramic spool after this episode. Sections $(\sim 0.1 \mathrm{~g})$ of the Johnson and Matthey and Goodfellow wires have been heated $\left(280^{\circ} \mathrm{C}\right)$ in deuterium, in the tritium analysis loop, in an attempt to drive out tritium contamination. No tritium contamination has been found in the wire by this procedure to within $0.2 \pm 0.1 \mathrm{nCi}$.
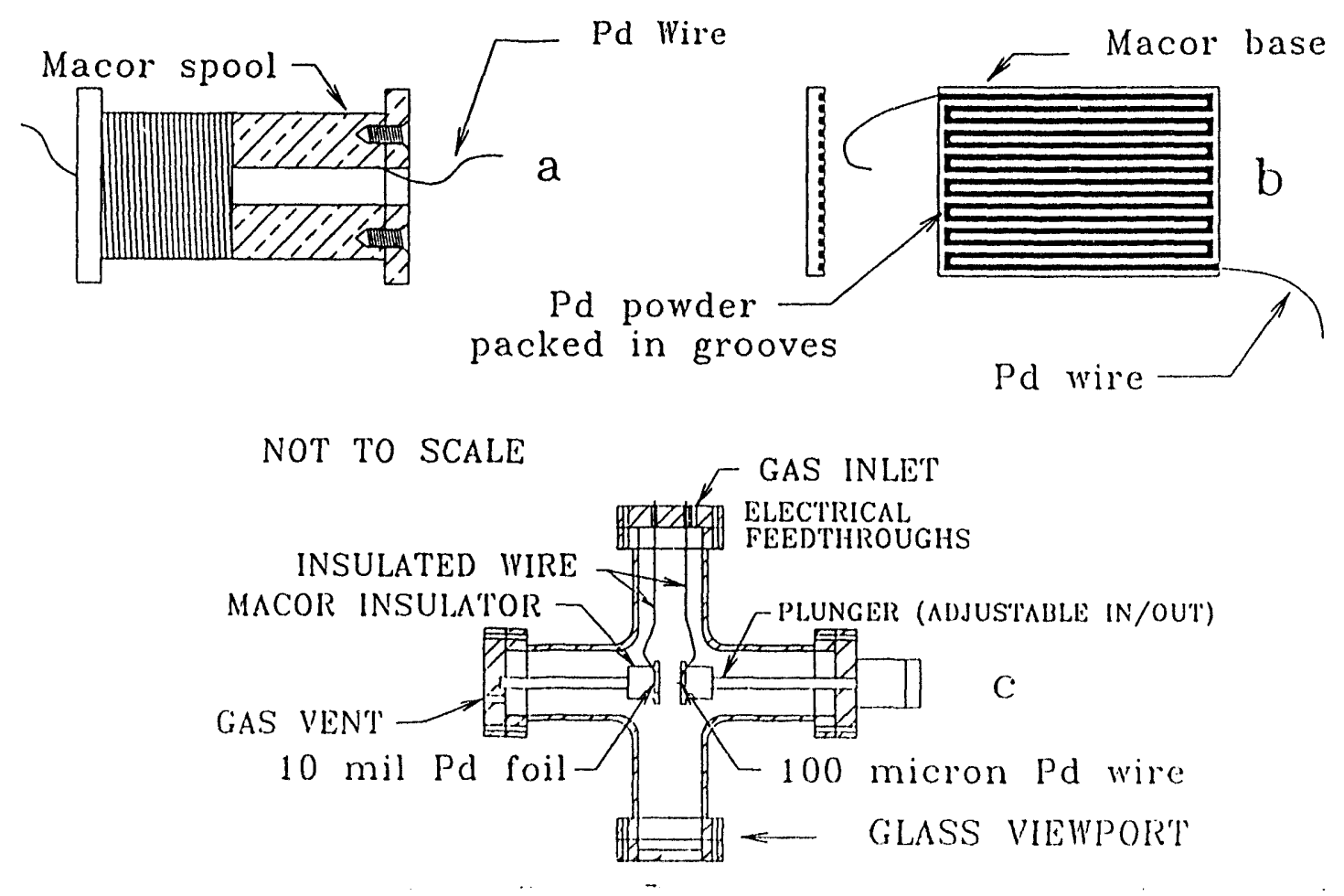

Figure 3. Diagram of the cell types used in this study.

The wire experiment with the largest tritium yield (batch W13918) is shown in Figure 4. It can be seen that the tritium level in the cell increases over the background drift rate at pulsed peak currents of greater than 3 amps. The background drift rate was measured prior to the placement of the cell in the loop and is for $\mathrm{D}_{2}$ gas, unfortunately the drift rate was rather high due 
to residual tritium contamination from a previous cell. Even so, the rates of tritium evolution from this wire exceed the background drift rate by a factor of 4.5. Other runs with this wire gave similar rates even though they were run in closed cells. Heating the wire to $100{ }^{\circ} \mathrm{C}$ prior to the current pulsing did not produce significant tritium over the background, but heating the wire after a run did produce significant evolution of the tritium. For instance, in the wire shown in Figure 4, $19.5 \mathrm{nCi}$ was evolved during the time the current was on but an additional $52 \mathrm{nCi}$ was released during the post heating of the cell.

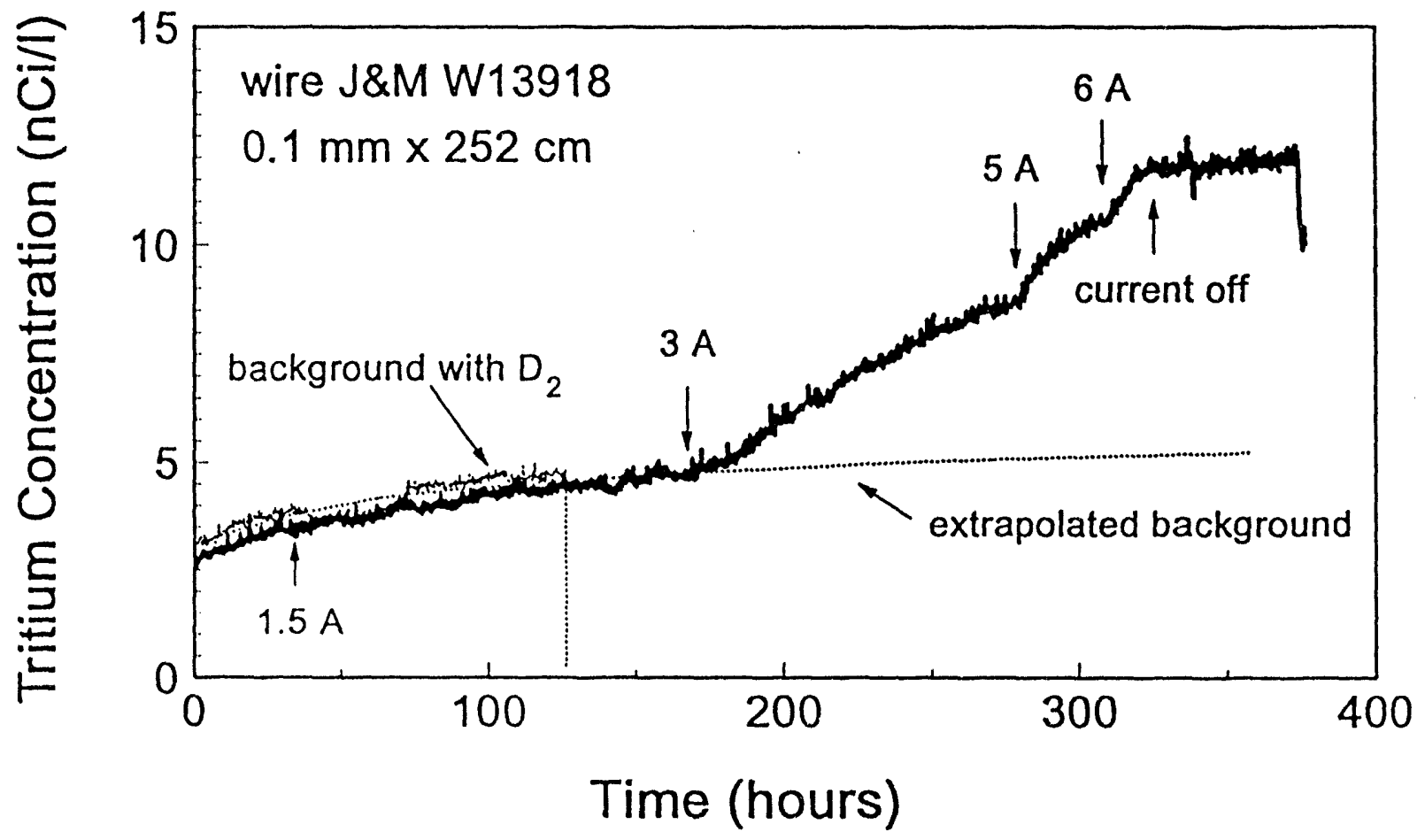

Figure 4. Tritium evolution from a Johnson Matthey wire.

One other wire was of note, and that was a Goodfellow $0.152 \mathrm{~mm}$ diameter wire. This wire was run in system 2 and produced $1.8 \mathrm{nCi}$ at a rate of $0.085 \mathrm{nCi} / \mathrm{h}$ before a pump and power failure terminated the experiment. This particular batch of wire was not as clean as the J\&M W13918 batch but was cleaner than other J\&M batches based on the amount of residue left on the ceramic spool.

\section{Powder Wire}

The seven powder wires were difficult to fabricate and run consistently. The largest result is shown in Figure 5 and occurred when an arc was apparently formed in the track. This produced an immediate and sudden rise in the tritium level as shown in the upper curve of Figure 5. The rate of tritium production $(\sim 5 \mathrm{nCi} / \mathrm{hr})$ during this episode far exceeds anything we have seen from the other types of cells. Unfortunately, none of the other cells could be made to arc in this way or produce much more than a few nanocuries as shown by the lower results in Figure 5 for cells 14 and 15 . The three powder track cells that were taken to BYU produced only an 
average of about $0.4 \pm 0.3 \mathrm{nCi}$.

While these cells were not reproducible, they did indicate that arcing was important. Therefore, we attempted to produce a plasma or an arc between plates and wires as described below.

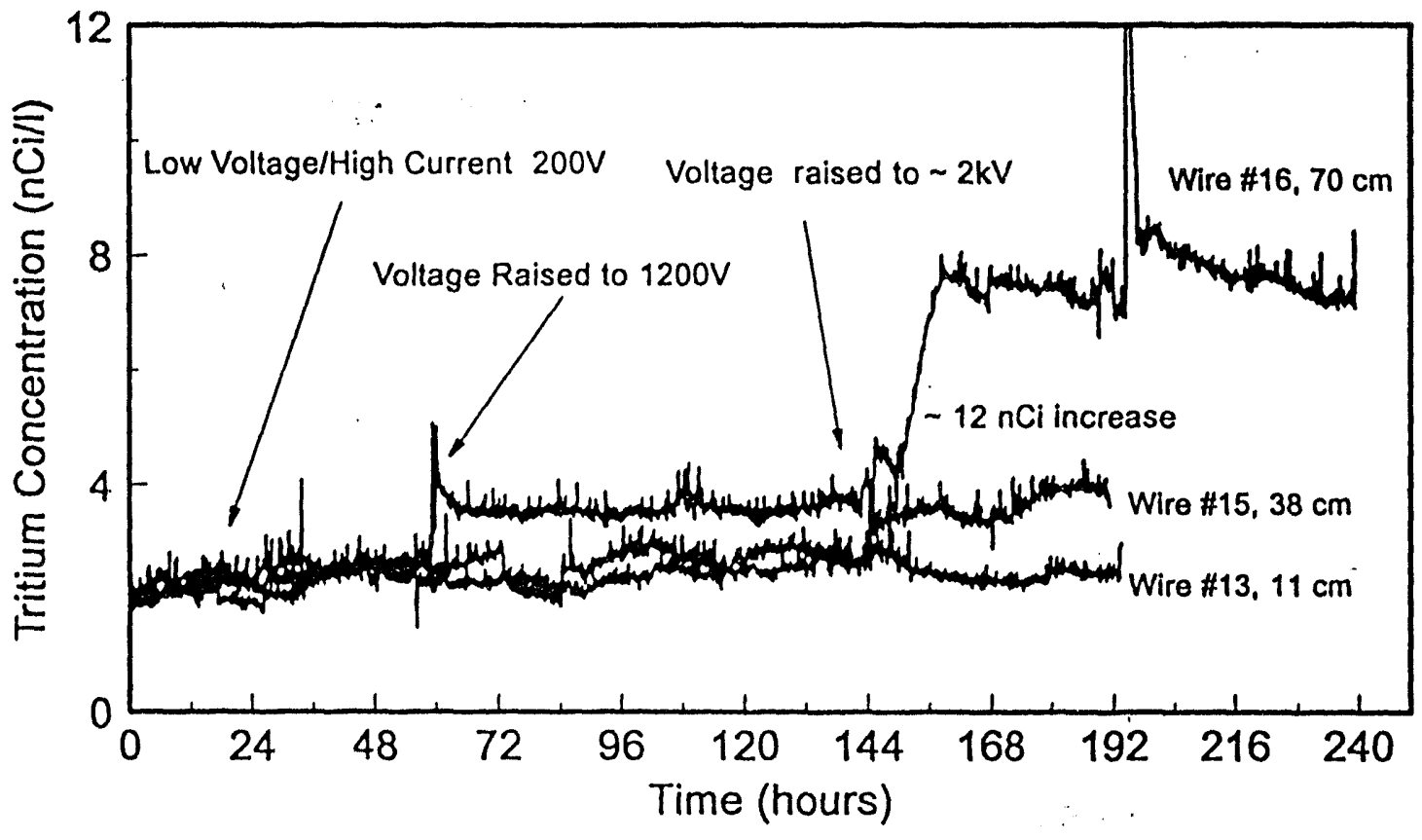

Figure 5. Tritium evolution from three powder wire cells. The conditions that produced the large, sudden, increase in tritium level in cell 16 have not been reproduced.

\section{Plasma Cells}

Of all the cells constructed, the most prolific and (seemingly) reproducible were the four plasma cells (Figure $3 \mathrm{c}$ ). The basic cell design of plasma 1,3 , and 4 was palladium plates $(0.25$ $\mathrm{mm}$ thick by $19 \mathrm{~mm}$ dia.) opposite palladium wires. Plasma cell 2 was constructed with two opposing palladium plates and exhibited a stable plasma but produced no tritium. These cells are similar to those reported by the Russian 8,9 and French ${ }^{10}$ researchers. Plasma one used J\&M $0.1 \mathrm{~mm}$ dia. wire while 3 and 4 used the Goodfellow $0.25 \mathrm{~mm}$ wire. The wire was pulsed negatively, $1 \mu \mathrm{s}$ pulse width at $500 \mathrm{~Hz}$, with respect to the plate. Peak currents of up to $12 \mathrm{~A}$ were used; voltages were from $2700 \mathrm{~V}$ (initiating the plasma) to $400-800 \mathrm{~V}$ (sustaining voltage).

Figure 6 shows the results for plasma 1 and plasma 2. Plasma one was only run for about 5 hours and produced about $0.6 \mathrm{nCi}$ during the time indicated. The rest of the time the plasma was activated it was arcing between the wall of the containment vessel and a connector. The expected signal level from the Femtotech for this plasma cell (based on pressure) is shown as the dotted line. It should be noted that the cell did not produce any tritium at 20 torr. The production only began after the pressure was increased to 80 torr. Similarly, the plate-plate cell produced a stable plasma at 20 torr but did not produce any tritium. It also did not produce any tritium at 600 torr where a spark was produced for several hundred hours resulting in copious amounts of fine palladium black on the inside of the vacuum chamber. As shown in Figure 6 after plasma 2 was 
run, the toop was pumped out and fresh $\mathrm{D}_{2}$ at 600 torr was introduced into the loop. The Femtotech level is seen to be approximately the same as during the period of arcing.

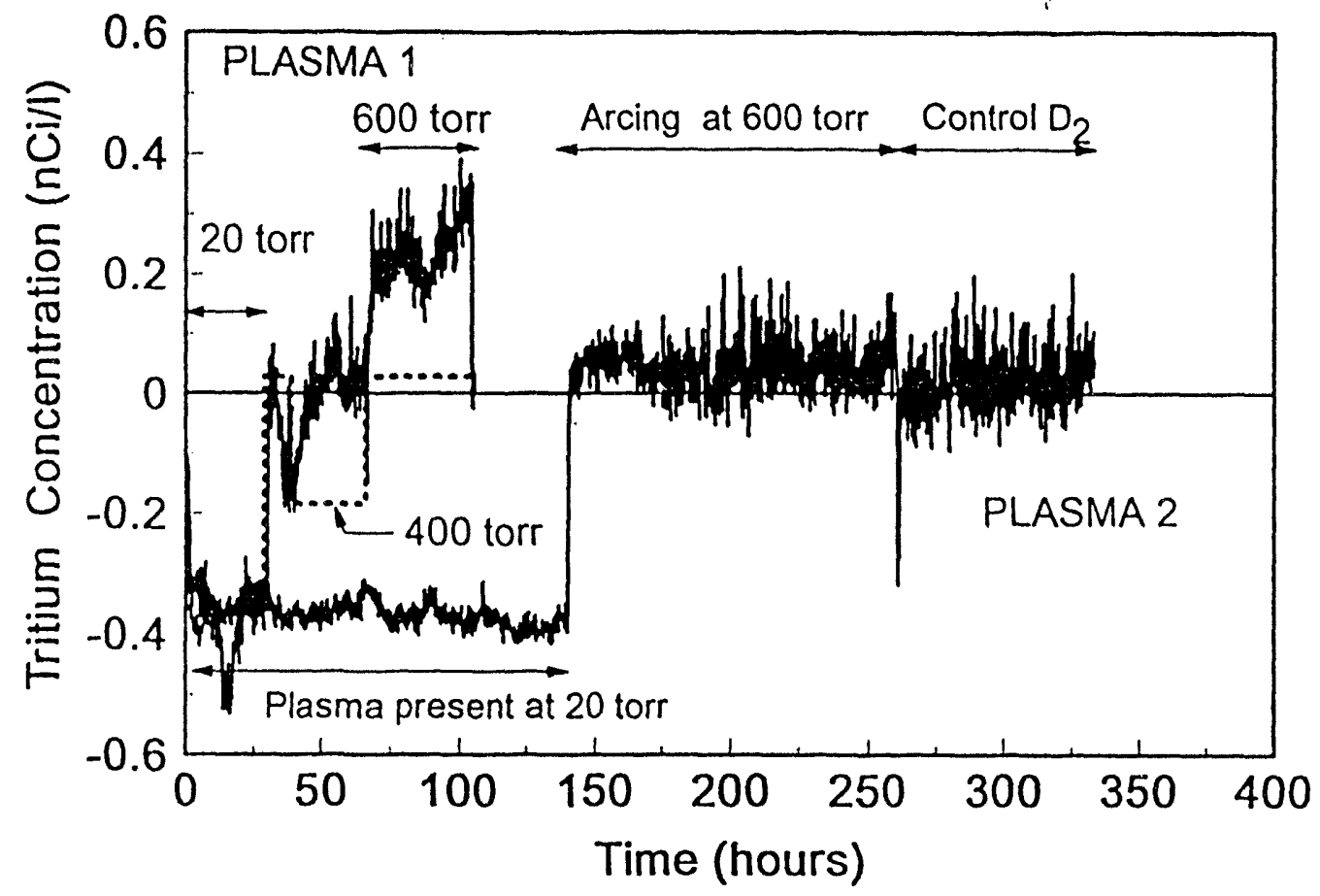

Figure 6. Results from the first two plasma experiments.

Since the plate-plate arrangement did not produce tritium, two attempts were made to replicate the wire-plate experiment. Both of these were very successful. Plasma 3 produced about $30 \mathrm{nCi}$ total and Plasma 4 produced nearly $102 \mathrm{nCi}$. For clarity, only the result for Plasma 3 is shown in Figure 7 although the result from plasma 4 is very similar. Wire and plate from the same batch were used for all of the plasma experiments described here.

The protocol for these cells is somewhat complicated, but in general, they were hydrided (120 torr) in the loop for a minimum of 24 hours then started with a peak current of $>4 \mathrm{~A}$, later the currents would be increased. The wire was charged negative during the pulse. Near the end of the runs the peak currents were on the order of $12 \mathrm{~A}$. The tritium generation rate was dependent on current, but was not linear with current and seemed to be saturating at currents over $8 \mathrm{~A}$. A $5 \%$ efficient ${ }^{3} \mathrm{He}$ slab neutron detector was placed directly under the cells and did not show any counts over background ( $\sim 2.3$ counts/s).

After a certain length of time, the dead volume in back of the plate was flushed. This resulted in the immediate release of a significant amount of tritium. This jump in tritium is labeled in Figure 7 as (a). Later, another flush and a final flush were given to the system. These are labeled (b) and (c). After the experiment the plates and wire were separately heated. The wire released about $12 \mathrm{nCi}$ of tritium while the plate had no measurable release. In Figure 7 the two dotted lines indicate the tritium release rate for two peak currents (5 and $6.5 \mathrm{Amps}$ ). Also plotted in Figure 7 are the two previous plasma run that indicate the stability and magnitude of the result from plasma 3. 


\section{DISCUSSION}

Tritium has been detected in Pd-D systems when excited by unipolar electrical pulses. There are five plausible sources for the excess signal. The tritium could be contamination in the palladium, the tritium could be hiding in the loop, the tritium could be coming out of the sample chamber, the tritium signal could be spurious and finally the tritium could be generated in the palladium by unknown processes.

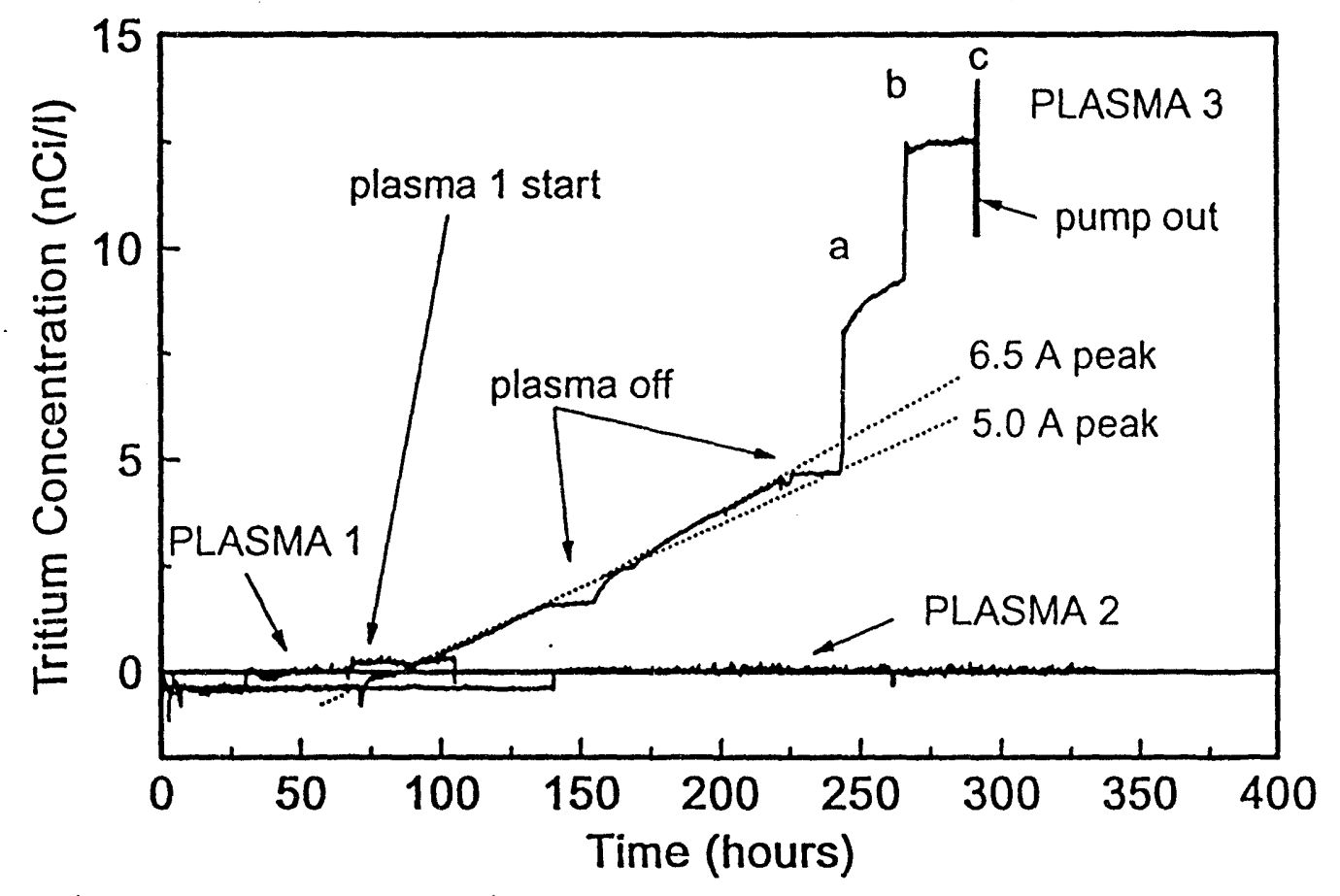

Figure 7. Tritium generation from a wire-plate plasma cell operated at 80 torr.

No tritium could be detected in any of the materials by a number of methods. However, since only samples of the material were used in the impurity analysis, the actual palladium in a sample could be "spot" contaminated. This type of contamination is unlikely to be intrinsic to the material since the materials are of very high "stated" purity. However, palladium wire that is drawn has to be lubricated either with oil or water and is usually fabricated from a thick right cylinder. Any spot contamination would tend to be drawn out and smeared throughout the length of the wire. Therefore, contiguous sections of wire should be cross contaminated. We attribute the residue and smoke seen from some of the wires to entrained lubricant. Tritium contaminated oil should be detected in all sections of the wire.

Spot contamination extrinsic to the wire, such as an oil residue left after opening the wire but before placing the wire in the container is a possible type of spot contamination. This is unlikely to occur in our samples since all parts are handled with new gloves and cleaned with ethanol prior to assembly.

Given the relatively large amounts of tritium seen in some of the samples, tritium should have been displaced from the wire by the hydriding process. As shown in Figures 4 and 7 there is no indication that the tritium would be evolved prior to running at high current densities. Post test, it was found that the tritium in the samples was more difficult to remove than expected, 
requiring temperatures on the order of $250^{\circ} \mathrm{C}$ for 10 hours. Peak temperature rise over ambient in the wire due to the current pulses is only $40^{\circ} \mathrm{C}$.

Finally, some wires and constituents of the plasma cells were heated at $80{ }^{\circ} \mathrm{C}$, in the analysis loop, for 12-24 hours prior to the activation of the cell. Tritium was evolved during the subsequent current pulsing rather than during the quasi-static heating. Similarly, the cell bodies and other constituent parts were heated to $200{ }^{\circ} \mathrm{C}$ for $24 \mathrm{~h}$ in an attempt to drive out any adsorbed tritium. No excess tritium could be detected in these tests.

The next most likely source of excess tritium is from hideout and tritium adsorption in the loop itself. System number one has been previously exposed to tritium for calibration purposes and previous cells have generated copious amounts of tritium that may have diffused into various parts of the system. Loop one has also been exposed to a volatile binder and trace amounts of pump oil that may have back diffused and could possibly trap tritium. It has been suggested that heated palladium would act as a catalyst and decompose the oil or binder contaminated with tritium. However, if the contaminated species can migrate to the palladium, it could also migrate to the ion chamber where it would give a direct reading.

System number one has been disassembled and the inside of the loop was swiped for tritium. A brownish deposit was found in some of the stainless tubing and this deposit was contaminated. We estimate, based on the swipes, that the system contained about $180 \mathrm{nCi}$ of adsorbed tritium. This amount of adsorbed tritium could seriously skew our results, but could not account for all the tritium seen in the largest of the events. In addition, tests were run where the cells were closed and only opened to the loop briefly to dehydrided the cells or where the cells were shut from the loop and then opened later with a resulting increase. We attribute the contamination to, primarily, the loop piping rather than the Femtotech because in one test, (during the cleanup after cell 42) the Femtotech was valved off from the rest of the loop and showed a low drift $(<0.02 \mathrm{nCi} / \mathrm{h})$ but when the valves were opened to the loop, the apparent tritium level immediately rose and the drift rate increased to $0.12 \mathrm{nCi} / \mathrm{h}$. The loop was heated to $423 \mathrm{~K}$ for this test to promote cleanup. While the contamination in the loop makes certain experiments more difficult to analyze, it does not negate the results since an overall total of 42 cells were run in closed cells.

Another possibility is that the ionization gauge may be directly affected by some agent originating in the cell such as water vapor, $\mathrm{CO}_{2}$, carbon or palladium black caused by the arcing. It is very unlikely that there would have been enough of a change in the composition of the gas to change the ionization efficiency by any significant amount since additions of $\mathrm{CO}_{2}$ ( 1 to 5 torr out of 1200 torr) are undetectable by the ion chamber. The fact that the chamber did not drift with the valves closed yet the system was orifting indicates that contamination of the ion chamber itself is not the primary factor. Furthermore, it is apparent that the ion chamber can be quenched by the presence of water, but we have no evidence that leakage current due to adsorbed water on the probe insulator will give anything other than a negative reading. A high steady reading due to a cloud of small particulates is unreasonable in view of the two filters in the system and because the tritium signal does not decrease whenever the gas flow was halted. The effect of particulates can be seen in Figure 5 where at about 194 hours the Fermtotech reading goes off scale for a few hours but returns to normal after the transient. This is typical of the response of the instrument to particulates.

From what has been discussed above it should be apparent that the loop contains various reservoirs for TDO hideout and storage. We believe the storage is of TDO rather than TD based 
on our extensive experience with similar systems that have been exposed to high levels of gaseous tritium. Adsorbed TDO is released slowly over a period of days as it exchanges with normal water or is deadsorbed from the surfaces of the loop by flushes of hydrogen deuterium or air. The difference in background drift rate is illustrater by the drift seen in Figure 4 versus the drift rate much later after multiple cleanings as shown in Figure 5 for the powder wire cell 13.

Because of the drift rate, tritium hideout, and water vapor effects make the powder cells difficult to interpret, we have concentrated on the wire, powder wire and plasma cells. These recent systems are very clean since they do not contain a volatile binder or any significant amount of water vapor. System 2 was also built to replace System 1 so that there would be no question as to the source of the tritium that was detected.

Most of the wire experiments have been done in situ in system 2 and have shown small or no amounts of tritium. The largest tritium release occurred from a $0.15 \mathrm{~mm}$ Goodfellow wire. Sections of this wire have been heated in deuterium with no release of tritium noted. All of the plasma experiments have been run in System 2 and have generated over $130 \mathrm{nCi}$ of tritium in a very clean system that over a period of months showed no increase over background with other types of cells.

The wire and the plasma experiments have confirmed the measurements made earlier on the powder cells that indicated the tritium output depended on current. In the wire, there appears to be a threshold current density, while in the plasma it there is a low current threshold and also saturation at high currents.

No significant neutron emission has been measured in these experiments or those at BYU using our materials and cells. Based on the tritium output and our previous neutron results, we would not expect to have detected any significant emission given the paucity of tritium found in the cells run at BYU. All of the samples have been subjected to gamma analysis both before during and after the experiments. No anomalous gamma lines, of any significance, have been detected.

\section{CONCLUSIONS}

Several methods of tritium production with palladium deuteride systems have been demonstrated. The tritium output depends on the current applied to the cells. Yet, the tritium yield is found to depend strongly on the type of palladium metal used (powder, foil or wire) and the type of experiment powder wire, wire, plasma. Various tests for tritium contamination confirm that there is no initial tritium contamination in the powder, foil, wire or other materials used in this study.

Annealing of the palladium seems to be necessary to reactivate foils after a deep dehydride. Lower values of stochiometry or lower gas pressures are less efficient for the generation of tritium. It is probably necessary to have at least a stoichiometry of 0.55 in the palladium.

The purity of palladium has varied in our experiments, with the wire experiments, it appears that very pure palladium is more effective that impure palladium in producing tritium. We also must conclude that we do not fully understand the full impact of impurities. We think this is partially a morphological or metallurgical issue since we have seen output from annealed as well as received palladium. However, palladium that been hydrided must always be annealed.

We do not expect that the nuclear process responsible for the tritium occurs in the plasma or that it is conventional two body $\mathrm{d}$-d fusion. The plate-plate experiment produced a stable 
plasma with no indication of tritium or neutron generation:

The success of these experiments relies on a non equilibrium condition existing in beta phase deuterated palladium. The plasma, arcing, and pulse heating are means to achieve this condition. We believe that the uncontrolled purity and metallurgical condition of most palladium electrodes is a major factor in explaining the unreproducible nature of many experiments.

\section{ACKNOWLEDGMENTS}

Many people were involved in a direct way with the experiments described here. Some of these were Ken Griechen, Roy Strandberg, Royce Taylor, Marie Bissett, and Steve Jones. We gratefully acknowledge the use of the first plasma cell from Dan Phelps and Ted Lautzerhiser of AMOCO.

\section{REFERENCES}

1. Claytor, T. N., Tuggle, D. G., Taylor, S. F.; Evolution of Tritium from Deuterided Palladium Subject to High Electrical Currents, Frontiers Science Series No. 4, Proceedings of the Third International Conference on Cold Fusion., October 21-25 Nagoya Japan., Ed. H. Ikegami, Universal Academy Press Tokyo Japan., 1993, p217.

2. Bockris, J. O'M., Chien, C-C., Hodko, D., Minevski, Z., Tritium and Helium Production in Palladium Electrodes and the Fugacity of Deuterium Therein, Frontiers Science Series No. 4, Proceedings of the Third International Conference on Cold Fusion., October 21-25 Nagoya Japan., Ed. H. Ikegami, Universal Academy Press Tokyo Japan., 1993, p231.

4. Wada, N. and Nizhizawa, K., 1989, Nuclear Fusion in Solid, Japanese Journal of Applied Physics, Vol. 28, No. 11, p L 2017.

5. Taylor, S. F., Claytor, T. N., Tuggle, D. G., and Jones, S. E., Search for Neutrons from Deuterated Palladium Subject to High Electrical Currents, See these procedings.

6. Pohts, J., INC-6, LANL, December 1992, private communication.

7. Cedzynska, K., Barrowes, S. C., Bergeson, H. E., Knight, L. C., and Will, F. W., 1991, Tritium Analysis in Palladium With an Open System Analytical Procedure, Fusion Technology, Vol 20, No 1, p 108, and private communication.

8. Karabut, A. B., Kucherov, Ya.R., Savvatimova, I.B., Nuclear Product Ratio for Glow Discharge in Deuterium, Physics Letters A, 170, 1992, p265.

9. Romodanov, V., Savin, V., Skuratnik, Ya. Timofeev, Yu., Nuclear Fusion in Condensed Matter, Frontiers Science Series No. 4, Proceedings of the Third International Conference on Cold Fusion., October 21-25 Nagoya Japan., Ed. H. Ikegami, Universal Academy Press Tokyo Japan., 1993, p307 .

10. DuFour, J., Cold Fusion by Sparking in Hydrogen Isotopes, Fusion Technology, Vol 24, 1993, p205. 

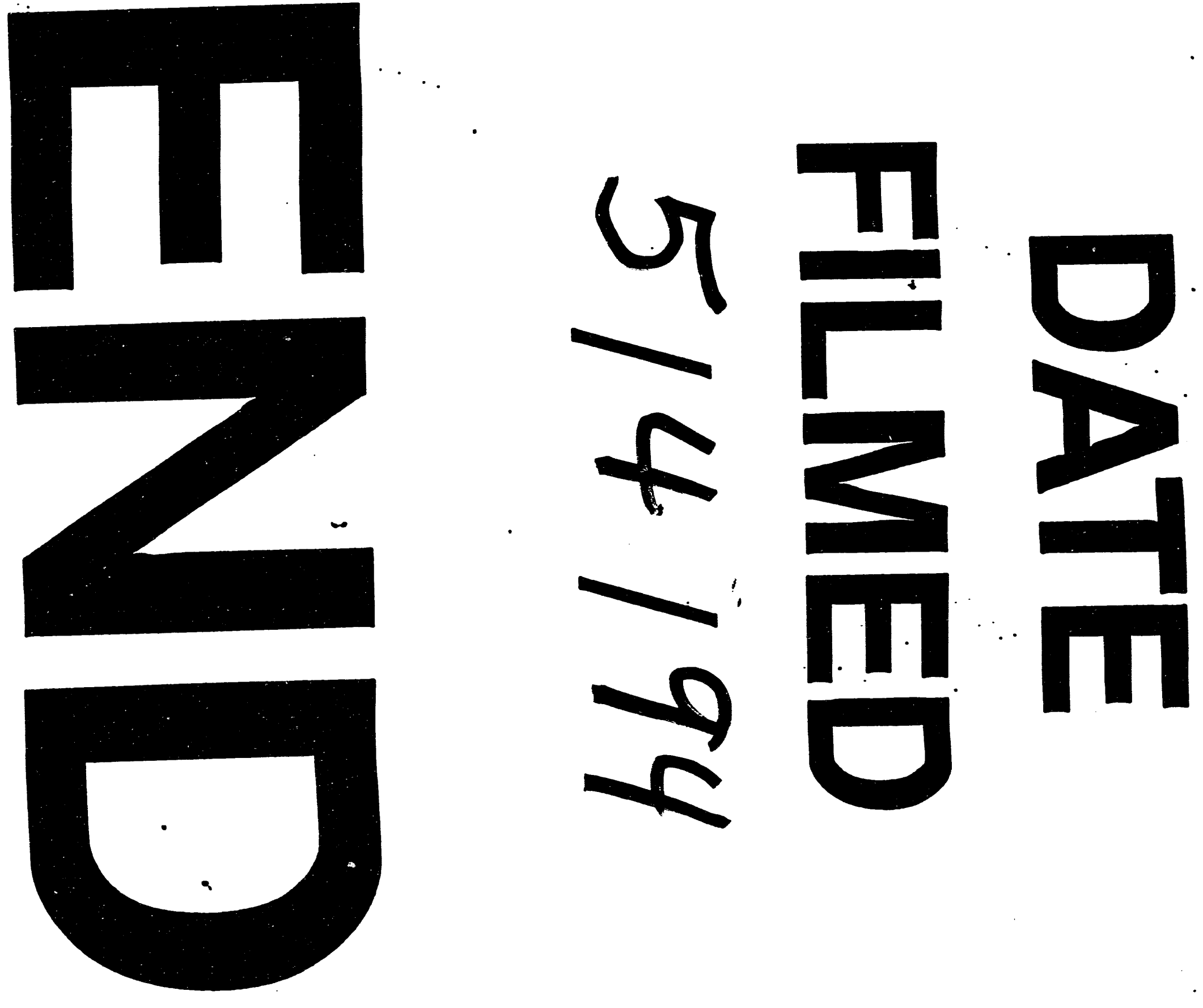
